\title{
Mujeres migrantes cuidadoras en flujos migratorios sur-sur y sur-norte: expectativas, experiencias y valoraciones ${ }^{1}$
}

\author{
Elaine Acosta González
}

Universidad Alberto Hurtado, Santiago, Chile. Email: eacosta@uahurtado.cl

Resumen: El artículo se aproxima a la problemática de la subjetividad y experiencia cotidiana de las mujeres migrantes que ejercen como cuidadoras domésticas en dos destinos migratorios altamente feminizados y con una alta concentración de mujeres inmigrantes en el sector doméstico de cuidados (España y Chile). Con ello se pretende indagar comparativamente en dos flujos migratorios (sur-norte y sur-sur) sobre las expectativas y motivaciones que configuran los modelos migratorios femeninos, el significado del trabajo de cuidado en la inserción laboral de las mujeres migrantes en las sociedades de destino, así como la valoración que esta labor tiene para sus protagonistas, tanto desde su dimensión emocional como de producción de bienes públicos. Los resultados presentados se basan en una investigación más amplia, cuya información primaria se obtuvo de la aplicación de 67 entrevistas en profundidad realizadas a distintos tipos de actores involucrados en la relación social de cuidado.

Palabras clave: feminización de las migraciones, trabajo de cuidados, subjetividad, flujos migratorios sur-norte y sur-sur.

\section{Female migrant care workers in south-south and south-north migration flows: expectations, experiences and appraisals}

\footnotetext{
Abstract: The paper addresses the problem of subjectivity and everyday experience of female migrant who work as domestic caregivers into two highly feminised migration flows with high concentration of women immigrant in domestic service (Spain and Chile). A comparative approach will be taken to examine south-north and south-south migration flows regards on the expectations and motivations that shape female migration patterns, the meaning of care work in the employment of migrant women in the receiving countries, as well as appraisal and meaning that care work has for its protagonists, both from the emotional perspective as of 'public good' production. The results presented here are based on a broader research project whose primary information was obtained from the application of 67 in-depth interviews with different actors involved in the social relation of care.

Key words: feminization of migrations, care work, subjectivity, southnorth and south-south migratory flows.
} 


\section{Mulheres migrantes cuidadoras na migração Sul-Sul e Sul-Norte: expectativas, experiências e avaliações}

Resumo: O artigo aborda o problema da subjetividade e da experiência cotidiana das mulheres migrantes que atuam como cuidadores domésticos em dois destinos de migração altamente feminizada e com uma alta concentração de mulheres imigrantes nos cuidados domésticos (Espanha e Chile). O propósito é investigar comparativamente em dois fluxos migratórios (sul-norte e sul-sul) sobre as expectativas e motivações que moldam os padrões de migração do sexo feminino, o significado do trabalho de cuidado no emprego de mulheres imigrantes nas sociedades de acolhimento, bem como a avaliação de que esse trabalho tem para os seus protagonistas, tanto a sua dimensão emocional como de produção de bens públicos. Os resultados apresentados são baseados em uma pesquisa maior cuja informação primária foi obtida a partir da aplicação de 67 entrevistas em profundidade com diferentes tipos de atores envolvidos na relação social de atendimento.

Palavras-chave: feminização da migração, trabalho de cuidado, subjetividade, fluxos migratórios sul-norte e sul-sul.

$* * *$

\section{Introducción}

“(...) los sentimientos, además de experimentarse, pueden ser objeto de reflexión”

(Hochschild, 2008:16)

Las migraciones internacionales de mujeres han jugado un importante papel en las transferencias, externalización y mercantilización de gran parte del trabajo de cuidados que otrora cubrían gratuitamente las mujeres en los hogares. Este proceso está estrechamente vinculado a la feminización de las migraciones, al generar fuentes de empleo crecientemente ocupadas por quienes vienen de países exportadores de mano de obra. Ha sido la "crisis de los cuidados' ${ }^{2}$ quien ha influido de manera significativa en este proceso. Las dinámicas resultantes han dado lugar a lo que en la literatura se conoce como 'fuga de cuidado' (care drain), un modelo donde la fuerza de trabajo femenina y flexible (habitualmente mujeres inmigrantes, indígenas y afrodescendientes) reemplaza el trabajo doméstico no remunerado y de cuidado que efectuaban las mujeres en los países desarrollados (Parella, 2007).

El concepto de cuidado o care es relativamente reciente para las Ciencias Sociales y aún es objeto de múltiples discusiones. Según la revisión y análisis que realiza Letablier (2007) sobre los orígenes, fundamentos y evolución del concepto, se reconoce la definición de C. Thomas (1993) como la mejor lograda. La autora identificaba cinco dimensiones para definir el care, a saber: la identidad del proveedor y del receptor de cuidados, el tipo de relación entre proveedor y receptor de cuidados, el contenido 
social del cuidado, el contenido económico de la relación y del trabajo, y, el marco institucional en el que se insertan los cuidados y los servicios.

Con todo, se trata de una noción polisémica, con un carácter multidimensional, pero que ha sido útil para destacar que el cuidado alude a una necesidad de todas las personas en todos los momentos del ciclo vital, aunque en distintos grados, dimensiones y formas. "Por cuidados podemos entender la gestión y el mantenimiento cotidiano de la vida y de la salud, la necesidad más básica y diaria que permite la sostenibilidad de la vida. Presenta una doble dimensión “material”, corporal -realizar tareas concretas con resultados tangibles, atender al cuerpo y sus necesidades fisiológicas- e "inmaterial”, afectivo-relacional -relativa al bienestar emocional. Cuidar es "hacerse cargo de los cuerpos sexuados" (Precarias a la deriva, 2005b) y de las relaciones que los atraviesan” (Pérez Orozco, 2006: 10).

En los últimos años, España y Chile se han constituido en casos emblemáticos de países que han atravesado una profunda crisis del cuidado y que en respuesta a ello han comenzado a importar mano de obra inmigrante, especialmente femenina, para hacerse cargo de las labores de reproducción social. Los estudios recientes realizados por las comunidades científicas española y chilena (Vicente y Setién, 2005; Martínez Buján, 2010; Oso y Parrella, 2012; Arriagada y Moreno, 2011 y Acosta, 2011, entre otros) han puesto en evidencia que el fenómeno de la feminización de las migraciones, tanto en los flujos migratorios sur-norte como en los sur-sur, no se produce solamente por los problemas económicos presentes en la sociedad de origen y la mayor demanda de mujeres inmigrantes para insertarse en ciertos labores u ocupaciones en la sociedad de destino. Se explica también como una oportunidad -devenida estrategia en algunos casos- para evadir, escapar o cuestionar el sistema de normas y pautas de socialización en el que las mujeres latinoamericanas despliegan sus proyectos de vida en las sociedades de origen. En función de esta complejidad de causas y posibilidades se configuran distintos modelos migratorios que van desde aquellos más centrados en la familia hasta los que se definen en función de las expectativas individuales de la mujer que migra.

Una vez en destino, la inserción de las mujeres migrantes en los mercados de trabajo de los países industriales avanzados ocurre en términos de segmentación, fenómeno que se comporta de manera muy similar en los países en vías de desarrollo. Este proceso se traduce en que para la gran mayoría de inmigrantes las oportunidades laborales se presentan sólo en aquellos empleos menos deseados por los nacionales, entre otros motivos porque la remuneración suele ser más baja que en el resto, tienen mayores niveles de precariedad laboral y son trabajos más devaluados socialmente. En consecuencia, son las mujeres las que terminan ocupando los empleos de menor prestigio social, entre otras razones porque son empleos ‘típicamente' femeninos.

De tal modo que han surgido nichos específicos de actividad 'de inmigrantes', principalmente de mujeres, que atraen flujos laborales con 
calificaciones y características determinadas. Uno de los casos emblemáticos lo constituye el trabajo doméstico y de cuidados. La incorporación laboral de las mujeres inmigrantes en estos flujos también se produce en empleos precarios, subvalorados y de bajo prestigio social y económico dando lugar a procesos de estigmatización y segregación laboral que dificultan su movilidad social (Zavala y Rojas, 2005; Mora y Valenzuela, 2009; Stefoni, 2009; Acosta, 2011).

Vale decir que, los trabajadores inmigrantes, y en particular las mujeres, tanto en Chile como en España, comparten el hecho de que, desde un punto de vista macroestructural, son sujetos que ocupan una posición de subordinación en la estructura ocupacional, constituyéndose en una característica destacada de sus trayectorias laborales (Thayer, 2011). En ambos destinos, la investigación social ha venido demostrando en forma sistemática cómo el empleo doméstico y de cuidados se ha convertido en un nicho laboral para la inmigración (IMSERSO, 2005; Martínez Buján, 2010; Tobío, et.al, 2010; Oso y Ribas, 2012; Herrera, 2011; Arriagada y Todaro, $2012)^{3}$.

En función de estos antecedentes, el presente artículo tiene por objeto analizar, en forma comparada en Chile y España, la valoración y significado que el trabajo de cuidados tiene para sus protagonistas, las mujeres cuidadoras, y el sentido que éste toma en sus proyectos migratorios. Para el logro de dicho objetivo pretendemos profundizar comparativamente en los destinos analizados, en los discursos de las mujeres inmigrantes cuidadoras domésticas. Por un lado, se intenta explorar la relación de los modelos modelos migratorios femeninos con las representaciones sobre el trabajo de cuidado y las razones para emplearse en ese sector. Por otro lado, es de interés indagar en la valoración del trabajo de cuidado a partir de la exploración del componente afectivo y de producción de bienes públicos, teniendo en cuenta las interpretaciones de las cuidadoras inmigrantes a través de su experiencia.

En cuanto a las especificaciones metodológicas, en el estudio se optó por la metodología cualitativa, a través de la utilización de la técnica de entrevista en profundidad, aplicada a un total de 67 personas (39 en España y 28 en Chile). Aunque en el estudio se realizaron entrevistas a tres tipos de actores: a) mujeres inmigrantes que realizan labores de cuidado de personas dependientes en forma remunerada en el ámbito doméstico (28 entrevistas), b) empleadores de mujeres inmigrantes que realizan labores de cuidado de personas dependientes en forma remunerada en el ámbito doméstico (26 entrevistas) y personas dependientes que son cuidadas por mujeres inmigrantes en el ámbito doméstico (13 entrevistas); para el análisis realizado en la elaboración de este artículo sólo se consideraron las entrevistas realizadas a las cuidadoras inmigrantes. La localización geográfica del estudio se realizó de la siguiente forma. Para las entrevistas en España, se escogieron dos áreas metropolitanas (Madrid y Bilbao). Madrid, por su alta concentración de personas inmigrantes y el área metropolitana de Bilbao, porque el porcentaje relativo de personas latinoamerica- 
nas respecto del conjunto de inmigrantes es muy elevado. En el caso de Chile, las entrevistas se realizaron en su totalidad en el área metropolitana de Santiago de Chile, dado que es la zona con mayor concentración de inmigrantes empleadas en el sector doméstico de cuidados. En el caso de España, el instrumento se aplicó durante los meses de marzo a junio de 2010, mientras que para Chile se utilizó el mes de noviembre del mismo año. Para el procesamiento y análisis de la información se utilizó el programa de análisis cualitativo Atlas Ti.

El artículo se estructura en cuatro partes. La primera analiza comparativamente las expectativas y motivaciones que configuran los modelos migratorios femeninos que se observan en uno y otro flujo estudiado. En la segunda parte, se muestra el significado del trabajo de cuidado en la inserción laboral de las mujeres migrantes en las sociedades de destino y su relación con el proyecto migratorio. En la tercera, se trabaja la dimensión emocional del trabajo de cuidado, dando cuenta de la tensión entre emoción y trabajo. Por último, se revisan los discursos que avalan la tesis del trabajo de cuidado como productor de bienes públicos.

\section{Expectativas, motivaciones y modelos migratorios femeninos relacionados con el trabajo de cuidado}

$\mathrm{Al}$ analizar las características sociodemográficas y las motivaciones de las mujeres entrevistadas para emprender el proyecto migratorio puede observarse cómo se ha ido remplazando el arquetipo tradicional de la mujer migrante -esto es, aquellas reagrupadas o emigrantes con el maridopara dar paso a las que se constituyen en pioneras del proyecto migratorio, ya sea en representación de la familia o como protagonistas de un proyecto migratorio personal propio. Respecto a las razones que impulsan la migración, en el discurso de las mujeres inmigrantes cuidadoras aparecen una pluralidad de motivaciones y objetivos que dan sentido a su proyecto migratorio.

En concordancia con los modelos migratorios femeninos predominantes (Figura 1), pueden agruparse las motivaciones de las mujeres en dos principalmente: las primeras y más extendidas, tanto en España como en Chile, centradas en la familia, y las otras, más vinculadas al proyecto de vida personal de la mujer migrante. Estas últimas aparecen en forma más predominante en las migrantes hacia España. Pese a la diversidad, en el caso de las entrevistadas para este estudio, predominan como motivaciones principales del proyecto migratorio los objetivos centrados en la familia. Estos pueden ir desde las urgentes necesidades económicas, que suelen estar muy vinculadas en el caso de las migrantes mujeres al deseo de logro de mejores oportunidades para los hijos, hasta los objetivos de reunificación familiar.

Las motivaciones de carácter económico afloran con claridad en los discursos. En España, las mujeres ecuatorianas entrevistadas, muchas de 
ellas con casi diez años de antigüedad en destino, emigraron en el contexto de la grave crisis económica y social que sufrió el país a fines de los años noventa, que trajo consigo la devaluación de su moneda, una elevada inflación y la posterior dolarización de su economía así como el encarecimiento repentino del coste de la vida (Pedone, 2003) ${ }^{4}$.

\section{Figura 1: Modelos migratorios femeninos}

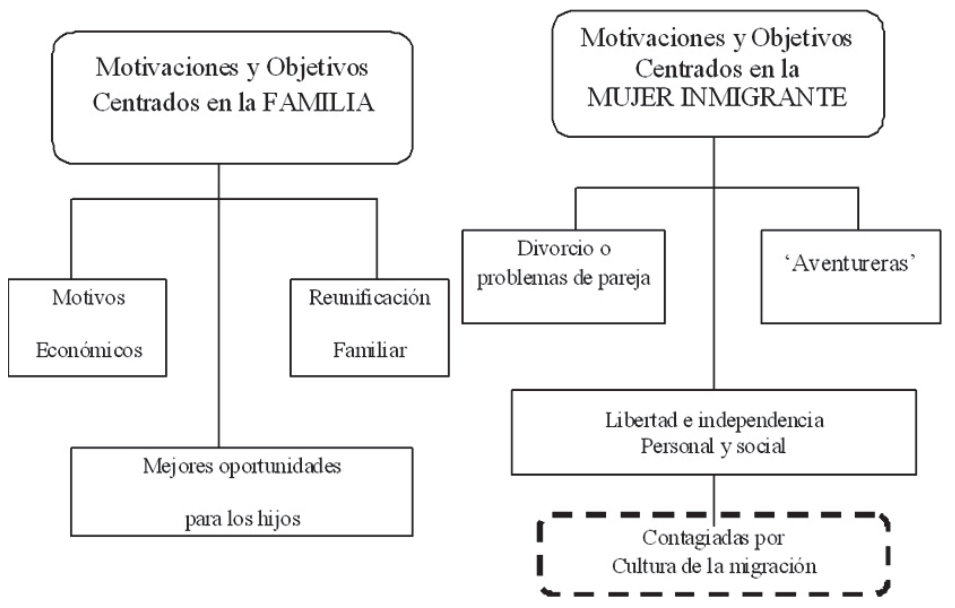

Fuente: Elaboración propia basada en tipología de Vicente y Setién (2005).

El caso de las migraciones peruanas no es muy distinto. En el país andino las causas de este fenómeno han sido diversas y muy complejas, pero aquellas de carácter económico siguen estando a la base de las motivaciones de la gran mayoría de los migrantes (Mujica, 2008). Los discursos de las mujeres peruanas que han migrado tanto a España como a Chile así lo confirman, siendo las razones de partida son muy similares a las de sus pares ecuatorianas.

Como se aprecia en la Tabla 1, las expectativas de mejoras económicas que en particular las mujeres esperan conseguir con la migración están estrechamente vinculadas a otra de las motivaciones que dan sentido y explican el proyecto migratorio de las cuidadoras entrevistadas en uno y otro destino: el logro de mejores oportunidades para los hijos. Sin embargo, las dificultades y consecuencias negativas que tanto para las madres migrantes como para sus descendientes en origen genera el proyecto migratorio condicionan que el objetivo de reunificación familiar sea planteado como prioritario. Esto puede apreciarse en forma más notoria en el discurso de las más jóvenes. Sus historias de vida durante la niñez y adoles- 
cencia ya han sido marcadas por la migración de sus madres, transformando sus roles y posición dentro de las relaciones familiares en origen. A causa de estas transformaciones, muchas de estas jóvenes presentan dificultades para continuar sus estudios, por lo que terminan planteándose la posibilidad de migrar como una vía u opción de recuperar cierta 'normalidad’ familiar al reencontrarse con sus padres y retomar su formación.

\section{Tabla 1. Motivaciones centradas en la familia}

\begin{tabular}{|c|c|c|}
\hline Tipo de motivación & España & Chile \\
\hline $\begin{array}{l}\text { De carácter } \\
\text { económico }\end{array}$ & $\begin{array}{l}\text { "En mi país se vino el caos del } \\
\text { cambio de moneda, el negocio se } \\
\text { vino abajo por el dólar, porque se } \\
\text { dolarizó, la gente intentó lo mayor } \\
\text { posible, pues ya sabes que la } \\
\text { peluquería es una cosa extra de la } \\
\text { vida cotidiana y empezó a } \\
\text { fastidiarse el negocio pues no me } \\
\text { llegaba ni para el negocio ni para } \\
\text { los gastos, entonces dije pues mira } \\
\text { tiro todo aquí y me voy a la } \\
\text { aventura" (cuidadora } \\
\text { ecuatoriana_España_09). } \\
\text { "Que mayor oportunidad que } \\
\text { venirme, me habia quedado sin } \\
\text { trabajo alli en Perú y bueno asi es } \\
\text { como llegué acá" (cuidadora } \\
\text { peruana_España_010). }\end{array}$ & $\begin{array}{l}\text { "La crisis del país, buscar mejoras } \\
\text { económicas para que mis hijos puedan } \\
\text { seguir estudiando" (cuidadora } \\
\text { peruana_Chile_063). } \\
\text { "Porque mi esposo no tenía trabajo y } \\
\text { allá si a los } 30 \text { años el hombre no } \\
\text { consigue trabajo, es muy dificil, } \\
\text { entonces tuve que venirme yo" } \\
\text { (cuidadora peruana_Chile_69). }\end{array}$ \\
\hline $\begin{array}{l}\text { Mejores } \\
\text { oportunidades para } \\
\text { los hijos }\end{array}$ & $\begin{array}{l}\text { "Mi motivo de venir para aquí en } \\
\text { primer lugar era por mis hijos, para } \\
\text { que tuvieran un futuro mejor que } \\
\text { alli en mi país" (cuidadora } \\
\text { ecuatoriana_España_014). }\end{array}$ & $\begin{array}{l}\text { "No me alcanzaba para darle los } \\
\text { estudios que ellos (los hijos) } \\
\text { necesitaban, lo que mandaba mi marido } \\
\text { tampoco alcanzaba, entonces dije, no, } \\
\text { voy a irme, que ellos también sean algo } \\
\text { en la vida, sean profesionales y eso es } \\
\text { lo que estoy logrando ahorita" } \\
\text { (cuidadora peruana_Chile_064). }\end{array}$ \\
\hline
\end{tabular}

Fuente: Elaboración propia.

En las entrevistadas encontramos algunas en cuya decisión del proyecto migratorio han jugado un papel importante las rupturas matrimoniales y las consecuencias, no solo económicas, que estos quiebres generan a nivel familiar y personal. "Me vine acá cuando me separé de mi pareja, entonces busqué otra opción para mejorar mi situación económica. Ese fue el motivo por el que yo me vine acá” (cuidadora ecuatoriana, España_041). 
La búsqueda de una mayor libertad e independencia personal y social es otro de los objetivos que se manifiestan en los discursos de las mujeres migrantes. El proyecto migratorio no solo es planteado como una estrategia familiar, sino de realización personal. Los deseos concretos manifestados pueden ir desde la acumulación de capital para la compra de una vivienda en origen hasta la terminación de estudios.

\section{Tabla 2: Motivaciones centradas en la mujer inmigrante}

\begin{tabular}{|c|c|c|}
\hline Tipo de motivación & España & Chile \\
\hline $\begin{array}{l}\text { Búsqueda de una } \\
\text { mayor libertad e } \\
\text { independencia } \\
\text { personal y social }\end{array}$ & $\begin{array}{l}\text { "(...) es que también quería mi vida } \\
\text { privada, mi vida personal, yo siempre } \\
\text { he sido independiente. Entonces } \\
\text { permití sólo que me ayuden en el } \\
\text { cuidado del niño nada más. Con los } \\
\text { objetivos que yo venía, hacer una } \\
\text { casa, regresar y poder retomar mis } \\
\text { estudios". } \\
\text { (cuidadora ecuatoriana_España_041) }\end{array}$ & $\begin{array}{l}\text { "Yo soy de esas personas que trabajó } \\
\text { siempre, para mi sin trabajar no podía } \\
\text { estar. Por eso fue una opción de } \\
\text { trabajo, si no se tiene nada allá... la } \\
\text { situación estaba en ese entonces } \\
\text { terrible". } \\
\text { (cuidadora peruana_Chile_060). }\end{array}$ \\
\hline
\end{tabular}

Fuente: Elaboración propia.

Dentro del grupo que manifiesta motivaciones centradas en sus propios proyectos personales, también se encuentran mujeres inmigrantes que la literatura ha clasificado como 'aventureras', cuyos proyectos migratorios están motivados por incentivos de búsqueda individual. Esta modalidad se presenta con mayor preponderancia en quienes han migrado hacia España. Suele ser el caso de las mujeres que cuentan con mayor nivel educacional y que no tienen hijos. En ellas, el proyecto migratorio se plantea como una decisión personal de búsqueda de mejoramiento de condiciones que en origen no eran necesariamente precarias. "En realidad no la pensé mucho, simplemente vine. Una vez aquí ya me tocó enfrentar porque devolverme no lo iba a hacer. Podía regresar, también por orgullo dije no, ¿que voy a regresar yo después de haber venido? No, ya está, aquí enfrento yo lo que me venga encima” (cuidadora ecuatoriana_España_048).

Sin embargo, como se trata en algunos casos de proyectos con escasa planificación, dichas mujeres se sorprenden de las dificultades que encuentran para insertarse en el mercado laboral ejerciendo sus profesiones. "Yo soy en mi país maestra. Me dijeron que podía trabajar con mis papeles aquí y fue una información que no era cierta. El problema que acá nosotros tenemos es el idioma, es el euskera. Cuando llegué aquí me animé y dije sí voy a trabajar y voy a ganar por el dinero (...) no lo pensé dos veces sino dije bueno me voy y cuando llegué aquí pues no era lo que me habían dicho" (cuidadora peruana_España_018y019). Como consecuencia, se produce una movilidad profesional descendente respecto de lo que habían con- 
seguido en sus países de origen en relación con el tipo de trabajo al que acceden en destino.

Existe otro grupo de mujeres cuidadoras de mayor edad que han migrado, principalmente haciaEspaña, con la motivación inicial y de carácter temporal de reencontrarse con alguna de sus hijas. En ellas, el horizonte del proyecto migratorio no está trazado con claridad, ni en términos de tiempo ni de objetivos. Reconocen la curiosidad y oportunidad de conocer y experimentar otras realidades sociales y culturales como un estímulo para emprender el proyecto. En el trayecto se insertan en el mercado laboral como cuidadoras, como una forma de costear su estancia y eventualmente de reunir recursos para el regreso a su país de origen: “yo no puedo estar sin trabajar, entonces eso ha sido, después de un tiempo regresar al país de uno con los hijos, ya no con los hijos sino con los nietos también” (cuidadora ecuatoriana_España_022).

Junto con los factores antes mencionados, las redes familiares y sociales aparecen de manera frecuente como una variable a la que se le atribuye gran importancia en tanto condiciona y facilita el proceso migratorio. Sabemos, sin embargo que, por sí solas, las redes familiares y sociales no explican la decisión migratoria. La multidimensionalidad de los procesos migratorios internacionales conlleva una complejización de vínculos que nos conduce a tener en cuenta, simultáneamente, la diversidad de aspectos que pueden estar incidiendo en las motivaciones de los migrantes, reconociendo el peso o importancia de cada uno desde la perspectiva del sujeto que los vive. Siguiendo a Pedone (2003), es necesario y urgente dejar atrás la visión idealizada de la familia como una unidad basada en lazos de cooperación y solidaridad, sino que al mismo tiempo es un lugar de conflicto y negociación, producto de lo cual sus componentes no toman necesariamente decisiones racionalmente óptimas.

\section{Necesidades y consecuencias de la inserción laboral en el trabajo de cuidado de las mujeres inmigrantes}

Las mujeres que migran con una oferta concreta de trabajo de cuidado tanto como las que emprenden camino sin horizonte laboral predefinido, viajan motivadas por la existencia de una demanda por este tipo de labores que saben que es creciente tanto en España como en Chile. Sin embargo, a pesar de esta certeza, muchas no son capaces de representarse con claridad las condiciones específicas en las cuales se desempeñarán. No es evidente que a la hora de plantearse el proyecto migratorio cuenten con una representación definida de las características o peculiaridades del tipo de trabajo que van a desempeñar en las sociedades de destino, salvo en el caso de las peruanas que migran a Chile. En la mayoría de estas mujeres, sus representaciones son más precisas. En su proyecto migratorio, aparece el trabajo de cuidado como una posibilidad de empleo altamente probable de concretarse, por cuanto 
conocen que suele ser la principal ocupación y la mejor remunerada a la que pueden acceder en Chile.

Sin embargo, las representaciones sobre el trabajo de cuidado en destino varían mucho de las que se proyectan en origen, especialmente en el caso de los modelos migratorios centrados en la mujer migrante. Tal suele ser el caso de las más jóvenes que llegan con expectativas de continuidad de estudios o trabajo en las profesiones en las que ya se han preparado en sus respectivos países de origen y por distintas razones terminan insertándose en el mercado de trabajo del servicio doméstico de cuidados. "Yo no pensé que era así como mi madre me decía y nunca tuve esa idea de venir a trabajar a cuidar personas mayores” (cuidadora ecuatoriana_España_017).

\section{Tabla 3: Conocimiento previo al proyecto migratorio sobre el trabajo de cuidado.}

\begin{tabular}{|l|l|l|}
\hline & \multicolumn{1}{|c|}{ España } & \multicolumn{1}{|c|}{ Chile } \\
\hline $\begin{array}{l}\text { Conocimiento } \\
\text { previo } \\
\text { proyecto } \\
\text { migratorio }\end{array}$ & $\begin{array}{l}\text { "La verdad es que yo no tenía ninguna } \\
\text { idea cómo era aqui" (cuidadora } \\
\text { ecuatoriana_España_012). }\end{array}$ & $\begin{array}{l}\text { "Tenía muchos antecedentes a veces de } \\
\text { compañeras, amigas que me decían, } \\
\text { legando allá te va a ser difícil porque a } \\
\text { "A mí meces no encuentras en lo que has } \\
\text { acá a cuidar, no me dijeron a qué..." } \\
\text { estudiado, o no vas trabajar. Lo único } \\
\text { que me decían era que iba a trabajar de } \\
\text { nana" }\end{array}$ \\
(cuidadora peruana_España_010).
\end{tabular}

Fuente: Elaboración propia.

Con independencia del nivel de conocimiento previo sobre el trabajo de cuidado, en los discursos aparecen un conjunto variado de razones que condicionan la inserción 'preferente' de las mujeres inmigrantes de origen latinoamericano en este sector Hemos agrupado estas 'necesidades sentidas’ que satisface el trabajo doméstico de cuidados en tres áreas: a) trabajo, b) vivienda, y c) regularización migratoria. A continuación se detallan estos discursos.

\section{Las necesidades de trabajo: 'hay más para trabajar en casas’}

El aumento de demanda de cuidadoras y la mayor disponibilidad de empleos que ofrece el sector del servicio doméstico de cuidados para las mujeres inmigrantes es la principal razón esgrimida para haberse empleado en este ámbito tanto por parte de las mujeres inmigrantes peruanas y ecuatorianas que llegan a España como las peruanas en Chile. Junto con la mayor oferta de empleos en el sector de los cuidados, aparecen en los relatos las características y condiciones del mercado laboral en las sociedades de 
destino -rigidez, alta segmentación, bajos salarios, discriminación, etc.como un impedimento adicional que se agrega a los prejuicios asociados a la condición de inmigrante para insertarse en las profesiones u oficios que traen de sus países de origen. De esta forma, sus oportunidades de trabajo están reducidas a ciertas labores de baja calificación, lo que no siempre se relaciona con el nivel de estudios que poseen. Así, aunque el nivel de estudios de la gran mayoría de las mujeres entrevistadas supera el nivel medio, en sus discursos se reitera la dificultad para continuar desarrollando sus oficios o profesiones en destino.

\section{Tabla 4: Discursos sobre las necesidades de trabajo.}

\begin{tabular}{|c|c|c|}
\hline & España & Chile \\
\hline $\begin{array}{l}\text { Mayor oferta de } \\
\text { trabajo doméstico } \\
\text { y de cuidados }\end{array}$ & $\begin{array}{l}\text { "Hay más para trabajar en casas, } \\
\text { ahíme tuve que meter a trabajar en } \\
\text { casas porque tanto tiempo no podia } \\
\text { estar sin trabajo" (cuidadora } \\
\text { peruana_España_039). } \\
\text { "Como los países de aquí ya están } \\
\text { envejeciendo hay más personas } \\
\text { mayores que necesitan más } \\
\text { cuidados,más dependencia de otras } \\
\text { personas" (cuidadora } \\
\text { ecuatoriana_España_009). }\end{array}$ & $\begin{array}{l}\text { "Fue la única opción que encontré en ese } \\
\text { entonces" } \\
\text { (cuidadora } \\
\text { peruana_Chile_060) }\end{array}$ \\
\hline
\end{tabular}

Fuente: Elaboración propia

\section{Las necesidades de regularización migratoria: 'no tienes tus papeles en regla, te cierran más las puertas'}

La histórica vinculación entre el empleo de hogar y la migración continúa siendo reforzada por los instrumentos jurídicos y de política migratoria, que no han sido capaces de modificar las condiciones de precariedad y vulnerabilidad de este sector. En un reciente artículo, Bridget Anderson (2012), señala cómo los Estados juegan un importante rol en el desarrollo de la demanda de trabajadores inmigrantes para el sector de los cuidados. En su texto muestra cómo las políticas sobre inmigración se constituyen en ‘soluciones políticas’ pragmáticas, reflejando y construyendo ideas y relaciones sociales sobre género, trabajo y nación. Las normativas nacionales sobre migración y trabajo doméstico, tanto en España como en Chile, son un claro ejemplo del tratamiento ambivalente y desigual de la migración (Stefoni, 2011; Pérez Orozco, A. y López Gil, S. (2011)

En los relatos emerge la cuestión de las mayores ‘facilidades' que ofrece el sector doméstico de cuidados para poder emplearse sin haber regularizado la situación migratoria como otra de las razones que se esgrimen para emplearse como cuidadoras en los hogares. Sin embargo, lo que 
a simple vista aparece como una oportunidad de inserción laboral para las mujeres inmigrantes y de regularización del estatus jurídico, que efectivamente lo es, se convierte en el corto plazo en una fuente de vulneración de derechos. Vale destacar que la manera en que incide la variable 'estatus migratorio' no se comporta de forma similar en cada flujo migratorio, siendo que las cuidadoras inmigrantes perciben que en Chile el proceso de regularización migratoria es más fácil y expedito que en España, a pesar de los obstáculos generales que todavía presenta.

\section{Tabla 5: Discursos sobre las necesidades de regularización migratoria.}

\begin{tabular}{|c|c|c|}
\hline & España & Chile \\
\hline $\begin{array}{l}\text { Necesidades de } \\
\text { regularización } \\
\text { migratoria }\end{array}$ & $\begin{array}{l}\text { "Entonces vienes } \\
\text { documentación, no tienes tus } \\
\text { papeles en regla, te cierran más las } \\
\text { puertas. Lo único que optas es } \\
\text { buscar en lo que hay, tratar de } \\
\text { trabajar en lo que haya. Pues en este } \\
\text { caso lo doméstico es lo que nos ha } \\
\text { salvado a muchas mujeres, a } \\
\text { muchísimas mujeres inmigrantes, } \\
\text { no solamente de mi país". } \\
\text { (cuidadora } \\
\text { ecuatoriana_España_009). }\end{array}$ & $\begin{array}{l}\text { "Yo llegué al país regularmente pero } \\
\text { después pasé a ser ilegal por problemas } \\
\text { de contrato de trabajo y me costó harto } \\
\text { regularizar todos mis papeles porque } \\
\text { cuando uno está ilegal no te pagan, } \\
\text { abusan de ti, porque no tienes los papeles } \\
\text { al dia. Todas esas cosas uno lo va } \\
\text { aprendiendo". } \\
\text { (cuidadora peruana_Chile_060). }\end{array}$ \\
\hline
\end{tabular}

Fuente: Elaboración propia.

\section{Las necesidades de vivienda: 'mi anhelo era irme interna'}

A pesar del apoyo que las redes familiares y sociales puedan ofrecer a las mujeres inmigrantes en relación con la búsqueda o disponibilidad de una vivienda, lo cierto es que esta es una necesidad perentoria difícil de resolver en la primera etapa del proyecto migratorio. Los altos costos de la vivienda junto a los escasos recursos económicos de la persona que migra dificultan su acceso. Frente a esta carencia, la modalidad de interna -como se denomina en España- o de 'puertas adentro' -como se llama en Chileen que se ejerce el trabajo de cuidado en el ámbito doméstico, deviene una alternativa práctica para sortear las dificultades iniciales, o que en el transcurso de la experiencia migratoria, se les presentan a las mujeres inmigrantes en relación con la vivienda.

Esta estrategia no solo facilita el acceso a una vivienda sino también resuelve la problemática de la habitabilidad en su conjunto, al disminuir significativamente los gastos en alimentación, transporte, vestuario y otros artículos de uso personal, permitiendo el ahorro y con él la posibilidad de cumplir las obligaciones contraídas de ayuda económica a la familia en 
origen a través de las remesas. En otros casos, los conflictos resultantes de la convivencia en destino al compartir un mismo espacio habitacional entre varias personas inmigrantes, ya sea con familiares, amigos o conocidos, se convierten en detonantes de la opción de trasladarse a vivir en forma permanente en el mismo domicilio en el que se presta el servicio de cuidado.

Tabla 6: Discursos sobre las necesidades de vivienda.

\begin{tabular}{|c|c|c|}
\hline & España & Chile \\
\hline $\begin{array}{lr}\text { Necesidades } & \text { de } \\
\text { vivienda } & \text { y } \\
\text { habitabilidad } & \end{array}$ & $\begin{array}{l}\text { "Mi anhelo era irme interna, porque yo } \\
\text { decía, voy a gastar en piso, voy a gastar } \\
\text { en comida, en transporte y eso de } \\
\text { estarme levantando de mañanita en ese } \\
\text { frío que para mí era nuevo y era tan } \\
\text { grande" } \\
\text { ecuatoriana_España_042). }\end{array}$ & $\begin{array}{l}\text { "Trabajando con cama, como dicen acá } \\
\text { puertas adentro, ahorras desde el } \\
\text { desayuno, el almuerzo, me ahorraba } \\
\text { todo, hasta los jabones, todo. Recibía } \\
\text { un sueldo entero que comparado al de } \\
\text { Perú era un poco más, no era ni medio } \\
\text { sueldo más que el de Perú, no era } \\
\text { mucho pero era algo más que } \\
\text { acumulando } 2 \text { o } 3 \text { meses, te lo podias } \\
\text { llevar integros". (cuidadora } \\
\text { peruana Chile 075). }\end{array}$ \\
\hline
\end{tabular}

Fuente: Elaboración propia.

Además de ocupar un lugar preferente en la inserción inicial laboral de las mujeres inmigrantes, en respuesta a las necesidades antes planteadas, el trabajo de cuidados deviene una actividad permanente en el itinerario laboral de este grupo. El perfil sociodemográfico de las mujeres inmigrantes entrevistadas así lo avala. En España confirma la existencia de estancias de larga duración en el trabajo de cuidados en el ámbito doméstico familiar -más de seis años en promedio-. Este tiempo no se diferencia mucho del promedio de años de duración de la experiencia migratoria, demostrando que este sector se convierte en un espacio laboral permanente para las mujeres inmigrantes latinoamericanas. "Con respecto al cuidado de personas mayores estoy ya prácticamente hace trece años. Siempre he trabajado en el tema de los cuidados” (cuidadora peruana_España_024). Por su parte, en Chile la inserción laboral de las inmigrantes peruanas en el mismo sector tampoco ocurre como una solución transitoria. Completan menos años de duración de su estancia en destino que las mujeres inmigrantes en España, pero su experiencia en el trabajo como cuidadoras en el ámbito doméstico, en promedio, es prácticamente idéntica a la duración del proyecto migratorio. "Acá tengo cuidando abuelitos, más o menos, desde el 2004” (cuidadora peruana_Chile_073).

Como resultado, la movilidad laboral que experimentan las mujeres inmigrantes que se insertan en los servicios de cuidados en el ámbito doméstico-familiar sigue el patrón de una trayectoria horizontal en donde el máximo progreso laboral se traduce en un cambio en la modalidad de 
jornada laboral (Martínez Buján, 2010; Arriagada, 2011). Para estas mujeres, el cambio hacia otro tipo de empleo es difícil de conseguir y, cuando acontece, se produce hacia otras ocupaciones del sector de los servicios como la hostelería, el comercio, los llamados 'call center', etc. Pero antes, se produce un movimiento dentro del propio trabajo de cuidados en el ámbito doméstico, cambiando de régimen y jornada.

La inserción y mantenimiento en el sector es producto de unas “condiciones de partida y de llegada impregnadas de la experiencia transnacional migratoria” (Escrivá, 2000: 333). En consecuencia, los itinerarios de inserción laboral en destino que las mujeres inmigrantes han recorrido no son 'libremente' escogidos. Además de las restricciones que la propia sociedad de llegada les pone a los inmigrantes, y a las mujeres en particular, la impronta de sus obligaciones familiares en origen, así como las necesidades que deben cubrir de manera prioritaria (empleo, regularización migratoria, vivienda) les condiciona a optar por determinados empleos y no por otros.

En la medida en que avanza el proyecto migratorio, las cuidadoras inmigrantes se percatan de las dificultades para moverse fuera del circuito del trabajo doméstico y de cuidados en el ámbito doméstico y familiar. Este proceso se convierte en un fenómeno similar a lo que otros estudios han identificado como "suelo pegajoso" del trabajo de cuidado. Las mujeres inmigrantes se ven adheridas a este tipo de labores vinculadas a la reproducción social, y por tanto devaluadas socialmente, lo que termina atrapán-

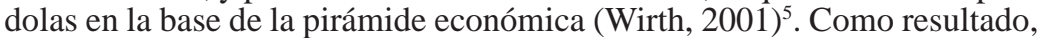
lo que en principio aparece como una oportunidad termina convirtiéndose en lo que se ha denominado "gueto de terciopelo", que define sectores profesionales y laborales, como el trabajo de cuidados, que se feminizan y acaban considerándose trabajos aptos para mujeres, en este caso inmigrantes, lo que inmediatamente conlleva a una reducción salarial, empeoramiento de las condiciones laborales y dificultades de ascenso. El trabajo doméstico de cuidados termina convirtiéndose en un enclave migrante en el interior del mercado de trabajo de las sociedades de destino (Thayer, 2011).

\section{La valoración del trabajo de cuidado desde la visión de las cuidadoras inmigrantes: entre el afecto y el trabajo}

A partir de la década de los noventa se desarrollan importantes avances en la construcción del concepto de cuidado, cuyo objetivo analítico consistía en avanzar en una definición que incorporase tanto los diferentes componentes de la actividad de cuidado como los distintos agentes involucrados en la provisión asistencial. Al respecto, los aportes de Ungerson (1990), Thomas (1993), Fisher y Tronto (1990), entre otras, en superar la dicotomía existente entre 'amor’ y ‘trabajo' en la clásica conceptualización del cuidado son de enorme relevancia. La distinción entre componentes físicos y emocionales provocaba que el 'trabajo de cuidados mercantilizado' 
(aquel en el que se recibe un salario por las tareas de atención prestada) fuera considerado de peor calidad al suponer que en él fallan los vínculos afectivos. Esto, porque se depositaba en la familia, y a las mujeres dentro de ellas, como las garantes del componente afectivo de la actividad de cuidado. En consecuencia, en aquel trabajo de cuidado no proporcionado por la familia la parte emocional queda desprovista de significado.

Se señala a Hochschild (1983) como una de las pioneras en reconocer el 'trabajo emocional' en las actividades del sector servicios en las que aparecen implicadas personas. Lo mismo se le atribuye a James (1989) quien ha reconocido en sus investigaciones la 'labor emocional' como un trabajo, así como la existencia de 'emociones' (cariño, afecto, amor...) en el ‘cuidado’ privatizado. En síntesis, como señala Martínez Buján (2010), el cuidado puede ser realizado en el ámbito doméstico y existir una relación mercantil a la vez que un apoyo emocional. El caso de las inmigrantes cuidadoras domésticas y el de las trabajadoras a domicilio de los SAD (Servicio de Ayuda a Domicilio) municipales en España son claros ejemplos. La autora sostiene que el cuidado, especialmente el que se desarrolla en el sector doméstico en el que se emplean mujeres inmigrantes, se ha convertido en un oficio de dar cariño, de otorgar amor y bienestar.

En los relatos de las mujeres inmigrantes entrevistadas para nuestra investigación aparece el aspecto emocional del trabajo de cuidar como aquel que más recompensa su trabajo, tanto para quienes se ocupan de personas mayores: "Lo mejor es que me gusta estar con personas mayores" (cuidadora ecuatoriana_España_017), como para quienes se hacen cargo del cuidado infantil: "El cariño de los niños yo creo que es lo más grande que uno pueda tener” (cuidadora ecuatoriana_España _048). Se trata de una percepción absolutamente compartida en ambos destinos analizados.

El 'trabajo emocional', que supone la presencia continua de una persona que ofrezca con su compañía bienestar y cariño a las personas en situación de dependencia (Martínez, 2010), es un aspecto valorado positivamente, por cuanto proporciona una recompensa intrínseca en calidad de 'retorno emocional', confiriéndole 'sentido' a su labor. Una labor que se realiza muchas veces en solitario, que no es visible públicamente ni tampoco socialmente valorada. Perciben además que es una ventaja comparativa con que cuentan en respuesta a una demanda sentida por las personas en situación de dependencia, que ni las familias ni los cuidados institucionalizados están en condiciones de ofrecer.

El problema se produce cuándo frente a la entrega de emociones no existe el reconocimiento que se espera, ni de parte de la familia empleadora ni de la sociedad en su conjunto. Como resultado, la dimensión emocional se constituye, en el aspecto que más desafía o tensiona a las mujeres inmigrantes cuidadoras, experimentando no solo sentimientos de gratificación, como se ha descrito, sino también de frustración, como se aprecia en la siguiente tabla. 


\section{Tabla 7: Discursos sobre el componente emocional del trabajo de cuidado}

\begin{tabular}{|l|l|}
\hline \multicolumn{1}{|c|}{ España } & \multicolumn{1}{|c|}{ Chile } \\
\hline $\begin{array}{l}\text { "Lo que no me ha gustado es que hay cosas } \\
\text { que de repente uno las hace por amor y por } \\
\text { cariño. Pero hay cosas que ellos tampoco lo } \\
\text { saben reconocer, eso es lo que no me gusta". }\end{array}$ & $\begin{array}{l}\text { "Son pocas las personas que hablan bien de los } \\
\text { inmigrantes porque dicen que algunas que vienen con } \\
\text { familia, dejan la familia allá y acá tienen marido o sea } \\
\text { desenfadototal. No les ven cosas, no hablan muy bien de } \\
\text { ellas. A veces yo quisiera darle vuelta a la página, que } \\
\text { ellos hablen bien. No todos son iguales, nosotros } \\
\text { venimos a trabajar, a forjarnos un futuro". } \\
\text { (cuidadora peruana_España_039) }\end{array}$ \\
\end{tabular}

Fuente: Elaboración propia.

Junto a esta tensión entre gratificación y frustración resultante del manejo del componente emocional del trabajo de cuidado, aparece el fenómeno de cómo quienes se desenvuelven en la actividad de cuidado son prisioneros de sus emociones, referido a la tesis del "prisoner of love" (Folbre, 2001). En comparación con la perspectiva clásica de los economistas, esta autora argumenta que el altruismo es consustancial al trabajo de cuidar. Una de las consecuencias que se derivan de ello es que los trabajadores no elevarán demandas laborales. El factor emocional, plantea England (2005), pondría a las cuidadoras en una posición vulnerable porque las desalienta a demandar remuneraciones más altas o a solicitar cambios en las condiciones laborales, porque ello podría tener efectos adversos para los beneficiarios de su trabajo. Al respecto, las entrevistadas se percatan de que el descanso laboral, por ejemplo, puede significar en ocasiones la discontinuidad y deterioro en el cuidado del dependiente. Así también el aumento de remuneraciones, especialmente en el caso de aquellos adultos mayores que se financian el cuidado con recursos propios, puede implicar el cese de la prestación de cuidado. En uno u otro caso, la cuidadora, presa de sus emociones no plantea -o posterga- sus demandas laborales de forma tal de no ocasionar perjuicio en los receptores de cuidado.

El alto nivel de involucramiento afectivo que se produce entre las cuidadoras inmigrantes y los receptores de cuidado suele ser un arma de doble filo. Los sentimientos de gratitud, generosidad, lealtad o altruismo que pueden identificarse en los relatos de las entrevistadas coexisten con el resentimiento, la autocomplacencia o el olvido de sí. En el desarrollo del trabajo de cuidado en el ámbito doméstico familiar, se entremezclan sentimientos de "gratitud y resentimiento, de generosidad y olvido de sí, de deuda y lealtad, autocomplacencia y altruismo. En definitiva, poder y explotación” (Vega, 2009: 97). Para la cuidadora inmigrante, ya sea que esté en Chile o en España, se torna complicada la gestión emocional del trabajo de cuidado en el ámbito doméstico familiar, especialmente cuando se trata 
de adultos mayores enfrentados a procesos complejos de deterioro de la salud, que en muchas ocasiones terminan con el fallecimiento de las personas que cuidan.

\begin{abstract}
"Cuando uno cuida mucho tiempo a una persona le queda ese vacío, ese que se la ha muerto alguien. Cuando se me murió mi viejita parece que hubiese sido algo mío, yo me sentía tan triste. Pero uno tiene que ir superando la situación. Entonces digo, bueno así es la vida! A veces cuando veía a mi viejita que sufría tanto decía: Dios mío, ¿por qué no se la llevará? Uno sufre junto con ellos, uno se apega a ellos como si fuera una familia” (cuidadora ecuatoriana_España_049).
\end{abstract}

La vulnerabilidad afectiva a la que están expuestas las cuidadoras inmigrantes, resultante del proceso migratorio y la separación de sus familiares y entorno habitual, suele aumentar al atender este tipo de dependencia. Se agrava, en la mayoría de los casos, debido a las carencias de competencias profesionales para gestionar el intercambio afectivo, especialmente cuando se producen episodios relacionados con la muerte y los procesos de duelo que de ella se derivan. La alta valoración del intercambio afectivo, justamente por ser un factor gratificante del trabajo de cuidado, produce que se entremezclen constantemente los planos intersubjetivos, generando confusión en la gestión cotidiana de la atención. Como señala Vega, las cuidadoras inmigrantes "mezclan, en términos generales, lo que el código profesional de la asistencia se empeña en separar: trabajo y afecto personalizado” (Vega, 2009: 111).

Por otra parte, el 'retorno' emocional del trabajo de cuidado no siempre se comporta del mismo modo. Antes bien, varía según el grupo de personas dependientes que le corresponda atender a la cuidadora. Otros estudios reconocen estas diferencias, señalando que en el cuidado infantil "la tarea emocional se considera más ligera psicológicamente, ya que se trata de personas con vitalidad y fuerza dinámica, de la cual carecen los mayores” (Martínez, 2010: 168). En España, donde es posible visualizar el contraste entre uno y otro tipo de cuidado, la mayoría de las cuidadoras inmigrantes de personas mayores entrevistadas, declaran valorar mejor el trabajo de cuidado con las personas mayores que con el grupo infantil, a pesar de la carga psicológica que implica y el esfuerzo físico que demanda el primero.

El estado de fragilidad física y emocional en el que se encuentra un grupo significativo de las personas mayores que cuidan, junto a la débil presencia y apoyo familiar, produce un vínculo afectivo importante y una alta dependencia de la cuidadora doméstica, quien puede manejarse con ciertos márgenes de libertad en su labor, debido justamente a la escasa supervisión que tienen los familiares de la persona dependiente. La cuidadora inmigrante puede aprovechar este tipo de circunstancias desfavorables para la persona que requiere cuidados y ejercer, 
aunque limitadamente, una cierta cuota de poder. "Las personas mayores yo creo que son un poquito más fáciles. Por ejemplo, el señor que yo cuidaba era una persona buenísima, él hacía lo que yo le decía” (cuidadora ecuatoriana_España_014). El manejo de las emociones termina "convirtiéndose en un recordatorio constante de la propia fragilidad” (Vega, 2009: 98), colocando en este caso al dependiente del lado de la deuda y la gratitud a su cuidadora.

En el caso del cuidado infantil también se suele producir un fuerte vínculo afectivo entre la cuidadora y los niños y niñas, que se manifiesta con mayor nitidez en aquellos que son cuidados desde pequeños por la misma trabajadora. Este aspecto aparece más destacado en las inmigrantes cuidadoras en Chile, por cuanto el cuidado infantil es la actividad predominante en la que se insertan las mujeres inmigrantes peruanas en dicho país. La recompensa emocional de esta labor está puesta en la responsabilidad que se atribuyen las cuidadoras en la proporción de bienestar y formación de los menores.

“Lo bueno es que tu llenas tu espíritu con los niños porque los niños son seres inocentes, lo más puro que puede haber y tú les das y los llenas con todo lo que puedas darle. Es el amor, el cariño que les tienes, con los juegos, y ellos te retribuyen con su cariño, con una sonrisa. Es lo más lindo que puede haber cuidar niños” (cuidadora peruana_Chile_063).

En algunas entrevistadas que tienen sus hijos en Perú, se percibe el fenómeno que ya se ha detectado en otros estudios en Chile, esto es, la producción de un 'traspaso' del afecto de madre a los niños o niñas que cuidan en sustitución del que no pueden entregar presencialmente a sus propios hijos (Arriagada y Moreno, 2011). En este punto se puede apreciar cómo no sólo el primer mundo 'extrae' amor del mundo más pobre, al comprometer los sentimientos que estas mujeres cuidadoras desplazan de sus propios hijos (que dejan lejos) hacia los menores que van a cuidar.

Por ejemplo, un aspecto que atenta contra el 'retorno emocional' positivo que produce el cuidado infantil, visión compartida por las cuidadoras que trabajan en Chile y en España, se refiere a las diferencias con sus empleadores en las pautas de crianza. A diferencia de las que se ocupan de personas mayores, el trabajo 'emocional' de las cuidadoras infantiles implica no solo proporcionar bienestar y cariño, sino también, aspectos relacionados con hábitos, disciplina y valores. En estos ámbitos, suelen producirse los principales conflictos, debido a la dificultad para establecer criterios comunes en la atención de los niños y niñas. Desde el punto de vista de las cuidadoras, los criterios de los progenitores en las sociedades de destino suelen ser más laxos y permisivos que los que ellas han experimentado en sus sociedades de origen en relación con las pautas de crianza. 
Tabla 8: Discursos sobre las diferencias culturales en torno a las pautas de crianza

\begin{tabular}{|c|c|}
\hline España & Chile \\
\hline $\begin{array}{l}\text { "Aquí-en España- la conducción de un niño } \\
\text { es mucho más dificil, aquí tienen a los niños } \\
\text { como muy tarde, y los tienen como en un } \\
\text { pedestal a los críos". } \\
\text { (cuidadora ecuatoriana_España_012). }\end{array}$ & $\begin{array}{l}\text { "Acá en Chile los niños son un poquito... malcriados no } \\
\text { es la palabra, quieren hacer lo que quieren. Lo que no } \\
\text { me gusta de acá es que son un poquito porfiados, bien } \\
\text { porfiados. Yo tengo mis hijos, pero uno sabe ya por } \\
\text { dónde agarrarlos, porque llegan a ser terribles. Si fueran } \\
\text { mis hijos les daría un jalón de orejas y a sus camas. Que } \\
\text { les contesten a su mamá y a su papá no me gusta, pero } \\
\text { no les dicen nada". } \\
\text { (cuidadora peruana Chile 056). }\end{array}$ \\
\hline
\end{tabular}

Fuente: Elaboración propia.

Estas dificultades generan impactos negativos en el desempeño laboral de las cuidadoras y provocan conflictos con los empleadores. La gestión del cuidado infantil les resulta más complicada, en contraste con la percepción del cuidado proporcionado a mayores. Perciben una sobrecarga de trabajo resultante de la despreocupación o descoordinación de sus padres en relación con la orientación de la crianza. Con ello se produce un desgaste emocional que disminuye los efectos positivos de la recompensa emocional intrínseca de este tipo de trabajo.

\section{La valoración del cuidado como producción de bienes públicos}

Bajo la premisa de que todo trabajo debiera implicar un beneficio para alguien -o de lo contrario no debiera ser realizado-, England (2005) revisa la perspectiva del cuidado como una producción de bienes públicos. Desde esta perspectiva, el trabajo de cuidado, tanto pagado como no pagado, produce más beneficios indirectos que cualquier otro tipo de trabajo. Se sostiene que el trabajo de cuidado incrementa las capacidades y destrezas de los sujetos receptores, tanto cognitivas como valóricas, normativas y de habilidades, y que el desarrollo de estas capacidades beneficiará no sólo al receptor del cuidado, sino a otros con quienes éste entre en contacto. En definitiva, el trabajo de cuidado contribuye al desarrollo de las personas, y ese desarrollo traerá beneficios generales posteriores, más allá de los recibidos por la propia persona. La autora interpreta el bien público como un incremento del capital social y por ende un generador de mayor confianza social.

En efecto, desde la perspectiva de las cuidadoras entrevistadas se percibe que este trabajo les reporta beneficios no solo a sí mismas sino 
también a quienes lo reciben. Este hecho permitiría considerarlo como un bien público. Para fundamentar esta tesis, se han agrupado los discursos sobre las valoraciones acerca del aporte del trabajo de cuidado en tres aspectos:

- Como facilitador del incremento de capacidades y destrezas de los sujetos receptores.

- Como enriquecedor del capital social de las cuidadoras inmigrantes.

- Como facilitador de la interacción social y generador de beneficios más allá de la relación directa de cuidado.

En el primer caso, como resultado de la interacción que se produce en la actividad de cuidado, las cuidadoras inmigrantes se autoperciben realizando un aporte a los receptores de cuidado frente al déficit de atención afectiva que padecen. Frente a esta carencia, las cuidadoras detectan que pueden cumplir un rol importante que pocos están dispuestos a asumir en las sociedades de destino, traspasando o desarrollando destrezas tanto cognitivas, valóricas o formativas. Además del cariño, en el caso del cuidado infantil las cuidadoras se autoperciben realizando un aporte que se traduce no solo en acompañamiento afectivo, sino también formativo.

Quienes proporcionan el cuidado valoran positivamente la posibilidad de adquirir un conjunto de capacidades y destrezas laborales y humanas que redundan en un aumento de su capital social. Perciben que la realización de este trabajo deviene una ganancia para sus propias vidas, en la medida en que les ha permitido adquirir autoconfianza y seguridad en sí mismas, ya sea por la posibilidad de enfrentarse a ambientes laborales distintos, como por tener que adaptarse a nuevos hábitos y costumbres culinarias, pautas de crianza, etc. De las personas mayores reconocen haber recibido aportes de su experiencia vital. De los niños y niñas que cuidan valoran la satisfacción personal que les produce acompañarles en su crecimiento. Este proceso es percibido como una ayuda en la continuidad de sus proyectos, llenando los vacíos emocionales ocasionados por la distancia con sus hijos y familias: 


\section{Tabla 9: Discursos sobre el trabajo de cuidado como producción de bienes públicos}

\begin{tabular}{|c|c|c|}
\hline & España & Chile \\
\hline $\begin{array}{l}\text { Facilitador del } \\
\text { incremento de } \\
\text { capacidades y } \\
\text { destrezas de } \\
\text { sujetos } \\
\text { receptores. }\end{array}$ & $\begin{array}{l}\text { "Las personas dependientes están } \\
\text { como falta de cariño" } \\
\text { (cuidadora ecuatoriana_España_013). } \\
\text { "Con los pequeños tú aprendes de } \\
\text { ellos y ellos de ti" } \\
\text { (cuidadora ecuatoriana_España_015) }\end{array}$ & $\begin{array}{l}\text { "A ellos les hago mucho aporte.Yo } \\
\text { mayormente me quedo con los niños } \\
\text { siempre, se desempeñan en lo que ellos } \\
\text { tienen que hacer" } \\
\text { (cuidadora peruana_Chile_074). } \\
\text { "La señora me agradece porque cuido bien } \\
\text { al joven, lo saco a pasear. Como ahora ya } \\
\text { no va al colegio, pasa metido aquí en la } \\
\text { casa entonces todas las tardes lo saco a } \\
\text { pasear" (cuidadora peruana_Chile_069). }\end{array}$ \\
\hline $\begin{array}{l}\text { Ampliación de } \\
\text { destrezas } \\
\text { afectivas y } \\
\text { relacionales. }\end{array}$ & $\begin{array}{l}\text { "Me llevo una gran satisfacción en mi } \\
\text { vida personal. Esto me ha ayudado } \\
\text { mucho también para seguir adelante. } \\
\text { El cariño de los niños yo creo que es } \\
\text { lo más grande que uno pueda tener" } \\
\text { (cuidadora ecuatoriana_España_048). } \\
\text { "He trabajado cuidando a personas } \\
\text { mayores y lo bonito es que vas } \\
\text { conociendo a mucha gente, } \\
\text { caracteres, sus sentimientos y te } \\
\text { ayuda a crecer también, aprendes } \\
\text { muchas cosas. La relación con las } \\
\text { personas te ayuda muchísimo a } \\
\text { entender, a perder miedos. A mí me } \\
\text { pasó eso, me ayudó a cambiar de } \\
\text { ideas, maneras de pensar" (cuidadora } \\
\text { ecuatoriana_España_041). }\end{array}$ & $\begin{array}{l}\text { "Lo bueno es que tu llenas tu espíritu con } \\
\text { los niños porque los niños son seres } \\
\text { inocentes. Lo más puro que puede haber y } \\
\text { tú les das y los llenas con todo lo que } \\
\text { puedas darle. Es el amor, el cariño que les } \\
\text { tienes, con los juegos, y ellos te retribuyen } \\
\text { con su cariño, con una sonrisa. Es lo más } \\
\text { lindo que puede haber cuidar niños" } \\
\text { (cuidadora peruana_Chile_063). } \\
\text { "Me di cuenta que un poco había cambiado } \\
\text { mi carácter, o sea a ser más comprensiva y } \\
\text { de repente más tolerante. Ahora me doy } \\
\text { cuenta que todos tenemos problemas y } \\
\text { todos tenemos malos momentos, soy un } \\
\text { poco más flexible. Ellos son también } \\
\text { personas muy buenas he aprendido que no } \\
\text { todas las personas son iguales". } \\
\text { (cuidadora peruana_Chile_075). }\end{array}$ \\
\hline $\begin{array}{l}\text { Incremento del } \\
\text { capital social }\end{array}$ & $\begin{array}{l}\text { "Una coge experiencia en trabajar } \\
\text { con personas mayores y al final } \\
\text { puede trabajar en residencias } \\
\text { también" } \\
\text { ecuatoriana_España_012). }\end{array}$ & $\begin{array}{l}\text { "He aprendido a cuidar niños } \\
\text { discapacitados, darle cariño como él } \\
\text { también a mi. A veces me dice tú buena } \\
\text { madre, buena mujer, me acaricia". } \\
\text { (cuidadora peruana_Chile_069). }\end{array}$ \\
\hline
\end{tabular}

Fuente: Elaboración propia.

De manera especial, este trabajo les ha permitido ampliar y profundizar en las destrezas afectivas y habilidades relacionales que de antemano les son reconocidas a la mayoría de las cuidadoras inmigrantes de origen latinoamericano. A una parte significativa de ellas, les resulta cómodo y cercano el trabajo con personas mayores, dada la relevancia familiar que los abuelos y abuelas han tenido en su propia formación. Algunas reconocen que este grupo suele facilitarles su labor, sin generar tensiones o conflictos con ellas o con sus familiares, hecho que impacta positivamente en su desempeño laboral. Adicionalmente, el trabajo de cuidado realizado en 
el ámbito doméstico familiar es percibido, en términos positivos, como una oportunidad de acumular conocimiento y experiencia que facilita con posterioridad la movilidad laboral dentro del sector, específicamente hacia los cuidados institucionalizados en residencias para personas mayores. En concreto, es valorado positivamente en tanto puente para conseguir un conjunto de competencias técnico-profesionales que, en la eventualidad de ser certificadas, les permitirán insertarse en ámbitos institucionalizados del cuidado, donde las condiciones laborales son mejores que en el sector doméstico familiar.

Por último, el incremento del capital social es resultado de un aprendizaje mutuo que enriquece tanto a cuidadoras como a receptores, así como a sus propias familias. Esta ganancia está estrechamente relacionada con el aumento de la interacción social al que las cuidadoras inmigrantes estás expuestas producto de su trabajo. Les toca interactuar con grupos de personas con historias, visiones y necesidades de cuidado diferentes. La variedad e intensidad de la interacción social que tiene lugar en el trabajo de cuidado, a pesar del habitual aislamiento que caracteriza esta actividad en el ámbito doméstico familiar, les posibilita a las cuidadoras inmigrantes una apertura mental que impacta positivamente sobre sus propias visiones de mundo.

En relación con los beneficios que van más allá de la relación de cuidado, algunos de los aspectos que son valorados positivamente por las cuidadoras inmigrantes están relacionados con las características del entorno laboral de la actividad que desarrollan. "Siento que es un trabajo quizá tranquilo y esa tranquilidad en otros trabajos no la tienes" (cuidadora ecuatoriana_España_009). Al ser realizado en el ámbito doméstico, perciben que cuentan con algunos márgenes de flexibilidad para organizarse en sus labores sin las molestias habituales de control o fiscalización de los jefes o los roces y conflictos con los pares, propios de ambientes laborales en los que se trabaja con más empleados. Al respecto, refiriéndose a sus empleadores comentan: "Nunca están detrás de mí, hay que te falta esto o lo otro. Aparte de que soy bastante responsable también, pero que no tengo a nadie encima, eso es otro beneficio” (cuidadora ecuatoriana_España_012).

\section{Consideraciones finales}

El análisis realizado nos ha permitido reflexionar en torno a las expectativas, experiencias y valoraciones de mujeres latinoamericanas (ecuatorianas y peruanas) que han emprendido proyectos migratorios tanto hacia el norte (España) como hacia el sur (Chile) y cuya trayectoria laboral en destino ha estado marcada por la inserción en el trabajo de cuidados realizado en el ámbito doméstico familiar. En cuanto a las expectativas, la investigación ha conseguido evidenciar la presencia de una pluralidad de motivaciones y objetivos que animan los proyectos migratorios de las mujeres inmigrantes en los dos destinos analizados. Este hallazgo permite avalar la tesis de la diversificación de los proyectos migratorios internacionales 
actuales, como un rasgo característico también de las corrientes femeninas (Vicente y Setién, 2005). Las motivaciones centradas en la familia, como se ha visto, continúan siendo las prioritarias y las más extendidas, lo que confirma que la migración contemporánea, incluyendo la femenina, responde más a una estrategia de supervivencia económica familiar que a un proyecto exclusivamente personal, que se toma o realiza en solitario. Sin embargo, en los discursos también se constató una presencia relevante de motivaciones vinculadas al proyecto de vida personal de la mujer migrante.

En este contexto, el trabajo de cuidados en el ámbito doméstico ha jugado un papel fundamental, por cuanto aparece como un horizonte laboral deseable, precisamente porque facilita que las mujeres puedan tomar en sus manos las riendas de su proceso migratorio. En el texto vimos como este tipo de trabajo responde a las 'necesidades sentidas' de este grupo al facilitar las demandas de trabajo, regularización migratoria y vivienda, prioritarias en las etapas iniciales de los proyectos migratorios.

El trabajo doméstico y de cuidados es reconocido en los discursos de las mujeres inmigrantes entrevistadas como una oportunidad laboral en la que proyectan insertarse desde el origen, con mayor claridad en las peruanas en Chile y menor consideración entre las que cuentan con mayor nivel educacional en ambos destinos. Este cambio puede ser resultado del camino previo ya recorrido por otras mujeres, las que transmiten las dificultades de inserción y movilidad laboral hacia otros sectores. Lo cierto es que las trayectorias relatadas, tanto en Chile como en España, demuestran escasa movilidad hacia otros sectores laborales. En consecuencia, el trabajo doméstico de cuidados termina convirtiéndose en un enclave migrante en el interior del mercado de trabajo de las sociedades de destino. Es efectivamente un nicho laboral que actúa como una puerta de entrada, pero al mismo tiempo deviene un callejón sin salida que configura y estigmatiza el trabajo de cuidados en el ámbito doméstico familiar como una actividad cada vez más feminizada y extranjerizada. Se trata de un círculo vicioso que condena a la población femenina inmigrante a ocupar los puestos de trabajo que están en la base de la pirámide económica, tanto por las malas condiciones objetivas que ofrecen como por el daño al estatus social que suponen, al ser una actividad devaluada socialmente.

No obstante lo anterior, el análisis realizado también ha permitido identificar que el trabajo de cuidado realizado por mujeres inmigrantes reporta importantes beneficios, tanto para quienes lo realizan como para quienes lo reciben. Desde la perspectiva de la producción de bienes públicos, los resultados encontrados permiten afirmar que se trata de un trabajo que produce una enorme rentabilidad social pero que experimenta un importante déficit de reconocimiento. El intercambio resultante de la relación social de cuidado ha significado un cambio en las maneras de ver y pensar la realidad que rodea a las mujeres inmigrantes $\mathrm{y}$, en ocasiones, de sus propias historias de vida y de relación con sus familias. También ha facilitado incrementar las capacidades y destrezas de los sujetos receptores, al tiempo que enriquece el capital social de las cuidadoras. Amén de estos 
beneficios, que suelen ir más allá de la relación directa de cuidado, el aspecto emocional del trabajo de cuidado resultó ser el que más desafía y tensiona a las trabajadoras. Al tiempo que les recompensa afectivamente les impide o dificulta acceder o exigir sus derechos, lo que reproduce relaciones de subordinación y explotación que atentan contra la revalorización del trabajo de cuidado y de quienes lo realizan cada vez con mayor presencia: las mujeres inmigrantes. 


\section{Notas}

${ }^{1}$ Este artículo está basado en los resultados de una investigación más amplia titulada Crisis del cuidado y migración. Análisis comparativo de flujos migratorios feminizados: surnorte y sur-sur. Proyecto FEM2009-09007-SUBPROGRAMME FEME: (2010-2012), Ministerio de Ciencia e Innovación, Gobierno de España.

${ }^{2}$ Por crisis de los cuidados se entiende "el complejo proceso de desestabilización de un modelo previo de reparto de responsabilidades sobre los cuidados y la sostenibilidad de la vida, que conlleva una redistribución de las mismas y una reorganización de los trabajos de cuidados, proceso que está cerrándose actualmente de forma no sólo insuficiente y precarizadora, sino reaccionaria, en la medida en que se basa en los mismos ejes de desigualdad social e invisibilidad de trabajos y agentes sociales que presentaba el modelo de partida” (Pérez Orozco, 2006: 9).

${ }^{3}$ El nicho laboral es creado por una demanda efectivamente existente con anterioridad a la llegada de la inmigración femenina, pero también por la forma particular de asentamiento en el mercado laboral, dada las características culturales del grupo o las particulares habilidades que se les atribuyen y las preferencias de las familias empleadoras hacia mujeres de estas nacionalidades.

${ }^{4}$ En Chile no se entrevistaron mujeres ecuatorianas cuidadoras, por no constituir un grupo significativo que se dedique a estas labores.

${ }^{5}$ El 'suelo pegajoso' comprendería así todas aquellas profesiones o labores feminizadas y que por ello pierden valor, disminuyendo también su salario. Constituye una nueva forma de esclavitud, que afecta fundamentalmente a las mujeres, y dentro de dicho grupo, a aquellas con mayores grados de vulnerabilidad, dentro de las que se encuentran las mujeres del mundo rural y las inmigrantes laborales. 


\section{Bibliografía}

Abel, Emily K., y Nelson, Margaret K. (1990), "Circles of care: An introductory essay”, en Emily K. Abel y Margaret K. Nelson (directoras): Circles of care: Work and identity in women' slives. State University of New York Press, Nueva York, p. 4-34.

Acosta, E. (2011), "Valorar los cuidados al estudiar las migraciones: la crisis del trabajo de cuidado y la feminización de la inmigración en Chile”, en Stefoni, C. (edit.), Mujeres inmigrantes en Chile. ¿Mano de obra o trabajadoras con derechos, Ediciones Universidad Alberto Hurtado, Santiago de Chile, p. 193-228.

Anderson, B. (2012), "Who needs Them? Care Work, Migration and Public Policy”, Cuaderno de Relaciones Laborales, Vol. 30, No. 1, p. 45-61.

Arriagada, I. y Moreno, M. (2011): “La constitución de las cadenas globales de cuidado y las condiciones laborales de las trabajadoras peruanas en Chile”, en Stefoni, C. (edit.) Mujeres inmigrantes en Chile. ¿Mano de obra o trabajadoras con derechos?, Ediciones Universidad Alberto Hurtado, Santiago de Chile, p. 149-192.

Arriagada, I. y Todaro, R. (2012), Cadenas globales de cuidados: El papel de las migrantes peruanas en la provisión de cuidados en Chile, ONUMujeres, Santiago de Chile.

England, P. (2005), “Emerging theories of Care Work”, Annual Review of Sociology, Vol. 31, pp. 381-399.

Escrivá, M. A, (2000), ¿Empleadas de por vida? Peruanas en el servicio doméstico de Barcelona, Papers, 60, p. 327-342.

Fisher, B. y J. Tronto (1990), “Toward a feminist theory of care”, en E. Able y M. Nelson, Circles of care: work and identity in women's lives, Albany New York, SUNY Press, p. 35-62.

Folbre, N. (2001), The invisible heart: Economics and family values, The New Press, New York.

Herrera, G. (2011), “Cuidados globalizados y desigualdad social. Reflexiones sobre la feminización de la migración andina”, Nueva Sociedad, $\mathrm{N}^{\circ}$ 233, p. 87-97.

Ídem (2012), "Repensar el cuidado a través de la migración internacional: mercado laboral, Estado y familias transnacionales en Ecuador”, Cuadernos de Relaciones Laborales, 30(1), 139-159.

Hochschild, A. (1983), The managed heart: commercialization of humans feelings, University of California, Berkeley. 
Hochschild, A. (2008), La mercantilización de la vida íntima. Apuntes de la casa y el trabajo, Katz Editores, Buenos Aires.

IMSERSO (2005), Guía de prestaciones para personas mayores y personas con discapacidad, Madrid.

James, N. (1989), Emotional labour: skill and work in the social regulation of feelings, Sociological Review, 37, p. 15-42.

Letablier, M. T. (2007), El trabajo de «cuidados» y su conceptualización en Europa, En Prieto, C. (Ed.). Trabajo, Género y tiempo social (pp. 6484). Madrid, España: Editorial Complutense.

Martínez Buján, R. (2009), “¿Y qué pasa con mi cuidadora? Inmigración, servicio doméstico y privatización de los cuidados a las personas dependientes”, Zerbitzuan: Gizarte zerbitzuetarako aldizkaria, Revista de servicios sociales, $\mathrm{N}^{\circ}$. 45, p. 99-109.

Martínez Buján, R. (2010), Bienestar y cuidados: el oficio del cariño. Mujeres inmigrantes y menores nativos, Consejo Superior de Investigaciones Científicas (CSIC), Madrid.

Ídem (2011), “La reorganización de los cuidados familiares en un contexto de migración internacional”, Cuadernos de Relaciones Laborales, Vol. 29, Núm. 1, 93-123.

Mora, C. (2008), “Globalización, Género y Migraciones”, Polis, Vol. 7, No. 20, pp. 285-297.

Mora, C. y Valenzuela, M.E. (2009), Trabajo doméstico: un largo camino hacia el trabajo decente, OIT, Santiago de Chile.

Mújica, J. (2008), Los migrantes y el Plan Nacional de Derechos Humanos 2006-2010, en "Conferencia Internacional Migraciones y Codesarrollo: En pos de buenas prácticas”, 19-21 de febrero de 2008, Lima (sin publicar).

Oso, L. y Parella, S. (2012), “Inmigración, género y Mercado de trabajo: una panorámica de la investigación sobre la inserción laboral de las mujeres inmigrantes en España”, Cuadernos de Relaciones Laborales, Vol. 30, Núm. 1, pp. 11-44.

Oso, L. y Ribas, N. (2012), “De la sorpresa a la incertidumbre: abriendo etapas en el estudio de la temáticas sobre género y migración en el contexto español”, Papers, 97/3, p. 511-520.

Parella, S. (2007), "Los vínculos afectivos y de cuidado en las familias transnacionales. Migrantes ecuatorianos y peruanos en España”, Migraciones Internacionales, Vol. 4, No. 2, pp. 151-188. 
Pedone, C. (2003), Tú siempre jalas a los tuyos. Las cadenas y las redes migratorias de las familias ecuatorianas hacia España, Tesis Doctoral, Universidad Autónoma de Barcelona.

Pérez Orozco, A. (2006), “Amenaza tormenta: la crisis de los cuidados y la reorganización del sistema económico”, Revista de Economía Crítica, № 5, pp. 7-37.

Pérez Orozco, A. y López Gil, S. (2011), Desigualdades a flor de piel: cadenas globales de cuidados. Concreciones en el empleo de hogar y políticas públicas. ONU Mujeres, Madrid.

Stefoni, C. (2009), “Migración, género y servicio doméstico. Mujeres peruanas en Chile”, en Mora, C. y Valenzuela, M. E., (ed.): Trabajo doméstico: un largo camino hacia el trabajo decente, OIT, Santiago de Chile, 191-232.

Thomas, C. (1982), “Deconstruyendo los conceptos de cuidados”, En Carrasco et al. (2011). El trabajo de cuidados. Historia, teoría y políticas, Catarata, Barcelona.

Thayer, E. (2011), “Trabajo y género: la condición social de inmigrante como referente para la definición de la identidad”, en Stefoni, C. (edit.), Mujeres inmigrantes en Chile. ¿Mano de obra o trabajadoras con derechos, Ediciones Universidad Alberto Hurtado, Santiago de Chile, 73-108.

Tobío, C., Agulló, Ma. S., Gómez, Ma. V. y Martín, Ma. T. (2010), El cuidado de las personas. Un reto para el siglo XXI, Colección de Estudios Sociales No. 28, Fundación La Caixa.

Ungerson, C. (1990), Gender and caring, Wheatsheaf Harvester, London.

Vega, C. (2009): Culturas del cuidado en transición. Espacios, sujetos e imaginarios en una sociedad de migración, Editorial UOC, Barcelona.

Vicente, T. y Setién, Ma. L. (2005), “Modelos migratorios femeninos”, en Julia González y María Luisa Setién (eds.), Diversidad migratoria. Distintos protagonistas, diferentes contextos, Universidad de Deusto, Bilbao.

Wirth, L. (2001), Breaking through the glass ceiling. Women in management. Ginebra: ILO Bureau for gender Equality (Summary). Disponible en http://www.ilo.org/public/english/support/publ/pdf/btgc.pdf

Zavala, X. y Rojas, C. (2005), Globalización, procesos migratorios y estado en Chile, en Centro de Encuentros Cultura y Mujer, Migraciones, globalización y género. En Argentina y Chile, Buenos Aires. 